\title{
Electrosynthesis and Characterization of Polypyrrole in the Presence of 2,5-di-(2-thienyl)-Pyrrole (SNS)
}

\author{
Nasser Arsalani ${ }^{1}$, Amir Mohammad Goganian"1, Gholam Reza Kiani³ \\ Mir Ghasem Hosseini ${ }^{2}$ and Ali Akbar Entezami ${ }^{1}$ \\ ${ }^{1}$ Polymer Research Laboratory, Department of Organic Chemistry, \\ Faculty of Chemistry, University of Tabriz, Tabriz, \\ ${ }^{2}$ Electrochemistry Research Laboratory, Department of Physical Chemistry, \\ Faculty of Chemistry, University of Tabriz, Tabriz, \\ ${ }^{3}$ School of Engineering-Emerging Technologies, University of Tabriz, Tabriz
}

Iran

\section{Introduction}

Electronically conducting polymers are a very popular research field among the chemists due to their use in a wide variety of marketable applications such as electrochromic devices [Mortimer et al., 2006; Sahin et al., 2005], polymer light-emitting diodes (LEDs) [Kraft et al., 1998], artificial muscles [Cortes \& Moreno, 2003], gas sensors [NicolasDebarnot \& Poncin-Epaillard, 2003], bio sensors [Geetha et al., 2006; Malinauskas et al., 2004] and corrosion protection of metals [Hosseini et al., 2007, 2008; Oco'n et al., 2005]. The preparation, characterization and application of electrochemically active, electronically conjugated polymeric systems are in the foreground of research activities in electrochemistry [Heinze et al., 2010]. Among the conducting polymers, polypyrrole has attracted a lot more interests [Jang \& Oh, 2004; Zhang et al., 2006; Chang et al., 2009]. This polymer is easy to synthesize both chemically and electrochemically, exhibiting good electrical conductivity and relatively good stability under ambient conditions, but lacking good electroactivity and redoxability.

In order to improve the electroactivity and redoxability of the electro-synthesized polypyrrole, another molecule containing conjugated system can be used during the electropolymerization of pyrrole. 2,5-di-(2-thienyl)-pyrrole (SNS) is one of the molecules containing conjugated system and have been studied by various electrochemical methods such as cyclic voltammetry, chronopotentiometry, and chronoamperometry under different conditions (changing the electrolyte, electrode, electrochemical potential range and etc) [Otero et al., 1998; Brillas et al., 2000; McLeod et al., 1986].

Entezami et al. have studied the electropolymerization of pyrrole and $N$-methyl pyrrole in the presence of 1-(2-pyrrolyl)-2(2-thienyl) ethylene (PTE) and 2-(2-thienyl) pyrrole (TP) by cyclic voltammetry in different conditions [Kiani et al., 2001]. Recently, we have studied the electropolymerization of thiophene and 3-Methyl thiophene in the presence of small amount 
of 1-(2-pyrrolyl)-2-(2-thienyl) ethylene (PTE). It was found that the conductivity, electroactivity and redoxability of polythiophene and poly(3-methyl thiophene) are improved in the presence of PTE [Kiani et al., 2008a, 2008b].

In this work, the effects of conjugated molecule (SNS) on the electropolymerization and electrochemical behaviour of pyrrole was investigated. Firstly, the electropolymerization of pyrrole and SNS were carried out separately by CV method. Secondly, the electropolymerization of pyrrole in the presence of small amount of SNS was carried out and then the influence of SNS on the electropolymerization and electrochemical behaviour of pyrrole was investigated. In addition, the effect of SNS addition on the electron transfer reaction of ferro/ferricyanide redox system on the polypyrrole film was studied and finally the conductivity of poly(Py-SNS) was determined by electrochemical impedance spectroscopy (EIS) method.

\section{Experimental}

\subsection{Materials}

Solvents were purified and dried according to the common procedures in the literature [Perin \& Armarego, 1998]. Acetic anhydride, ammonium acetate, ferro/ferricyanide were purchased from Merck and lithium perchlorate were bought from Fluka and all of them were used directly.

\subsection{Preparation of 2,5-di-(2-thienyl)-pyrrole (SNS)}

2,5-di-(2-thienyl)-pyrrole (SNS) was prepared by the method described by Wynberg and Metselaar [Wynberg \& Metselaar, 1984]. The yield was improved by refluxing the solution of the intermediate 1,4-di-(-2-thienyl)-1,4-butanedione $(3 \mathrm{~g})$ with ammonium acetate $(40.3 \mathrm{~g})$, glacial acetic acid $(120 \mathrm{ml})$ and acetic anhydride $(24 \mathrm{ml})$ overnight under a nitrogen atmosphere. The reaction mixture was then poured into $250 \mathrm{ml}$ of distilled water and the resulting dark-green solid was chromatographed over a silica gel column with dichloromethane: hexane (3:2) elution to give SNS with 75\% yield, as pale yellow crystals of melting point $82-83^{\circ} \mathrm{C}$.

IR(KBr): $3490 \mathrm{~cm}^{-1}(\mathrm{~N}-\mathrm{H}) ;{ }^{1} \mathrm{H} \mathrm{NMR}\left(\mathrm{CDCl}_{3}\right)$ : $\delta: 6.2(2 \mathrm{H}, \mathrm{d}), 6.8(6 \mathrm{H}, \mathrm{m}), 8.0(1 \mathrm{H}, \mathrm{s})$.

\subsection{Electropolymerization method and conductivity measurements}

The electropolymerization was carried out using digital potentiostate/galvanostate (Autolab PGSTAT 30). A glassy carbon (GC) disk (2 $\mathrm{mm}$ diameter) as working electrode, a platinum wire as a counter electrode and $\mathrm{Ag} / \mathrm{AgCl}$ as a reference electrode were used. Acetonitrile was distilled over $\mathrm{P}_{2} \mathrm{O}_{5}$ and lithium perchlorate was used as an electrolyte in 0.1 $M$ concentration. The electropolymerization of pyrrole $(0.5 \mathrm{ml}, 7.4 \mathrm{mmole})$ and SNS (16 mg, $0.074 \mathrm{mmole}$ ) in $0.1 \mathrm{M} \mathrm{LiClO}_{4} /$ acetonitrile electrolyte were performed separately in two different potential ranges vs. $\mathrm{Ag} / \mathrm{AgCl}$ at the scan rate of $50 \mathrm{mV} \cdot \mathrm{s}^{-1}$. Similar conditions were adopted for the electropolymerization of pyrrole in the presence of SNS (7.4 mmole: 0.074 mmole). In the study of the cyclic voltammetry experiment of electron transfer, $1 \mathrm{mM}$ ferro/ferricyanide in the $1 \mathrm{M} \mathrm{H}_{2} \mathrm{SO}_{4}$ media at $50 \mathrm{mV}$.s $\mathrm{s}^{-1}$ scan rate was used.

For the EIS measurements, the AC frequency range extended from $100 \mathrm{kHz}$ to $10 \mathrm{mHz}$, a 10 $m V$ peak-to-peak sine wave was as the excitation signal. Both real and imaginary 
components of the EIS in the complex plane were analyzed using the Zview(II) software to estimate the parameters of the equivalent electrical circuit. A computer-controlled potentiostate (PARSTATE 2263 EG\&G) was used for EIS measurements.

\section{Results and discussion}

\subsection{Electrochemical synthesize of polymers}

The electropolymerization of pyrrole was performed by cyclic voltammetry in the potential range of -100 to $900 \mathrm{mV}$ through 15 scans. As shown in figure 1, at the first scan, there is an anodic peak at ca. $800 \mathrm{mV}$. By continuing electropolymerization through second scan, another anodic peak was observed at $550 \mathrm{mV}$ indicating formation of polypyrrole. After the formation of black colored polymer film on the GC electrode surface, the electrode was taken out from electrochemical cell and was washed with acetonitrile. For the resulted polymer, the cyclic voltammograms at various scan rates were shown in figure 2 indicating a quasi-reversible behaviour.

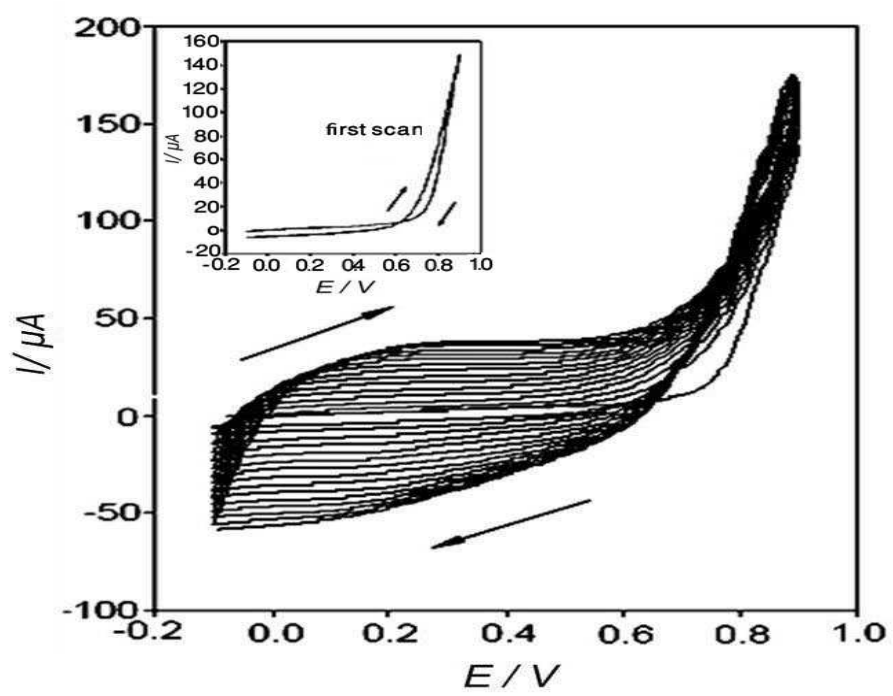

Fig. 1. Cyclic voltammograms of $7.4 \times 10^{-3} \mathrm{M}$ pyrrole in $0.1 \mathrm{M} \mathrm{LiClO}_{4} / \mathrm{CH}_{3} \mathrm{CN}$ electrolyte at scan rate $50 \mathrm{mV} / \mathrm{s}$ vs. $\mathrm{Ag} / \mathrm{AgCl}$

The cyclic voltammetry investigations of SNS were carried out in the potential range of -400 to $1500 \mathrm{mV}$ (Fig. 3). At the first scan two anodic peaks at ca. 570 and $1300 \mathrm{mV}$ were observed resulting from the oxidation of SNS. In the backward scan from 1500 to $-400 \mathrm{mV}$, there is one peak indicating a quasi-reversible reaction. At the second scan, a new anodic peak current was observed indicating formation of the electroactive poly(SNS) with an ionic structure. As shown in figure 3 , after 7 scans, the second anodic peak at $1300 \mathrm{mV}$ was eliminated. The cyclic voltammogram of poly(SNS) in the potential ranges between -400 to $1000 \mathrm{mV}$ at various scan rates was shown in figure 4. 


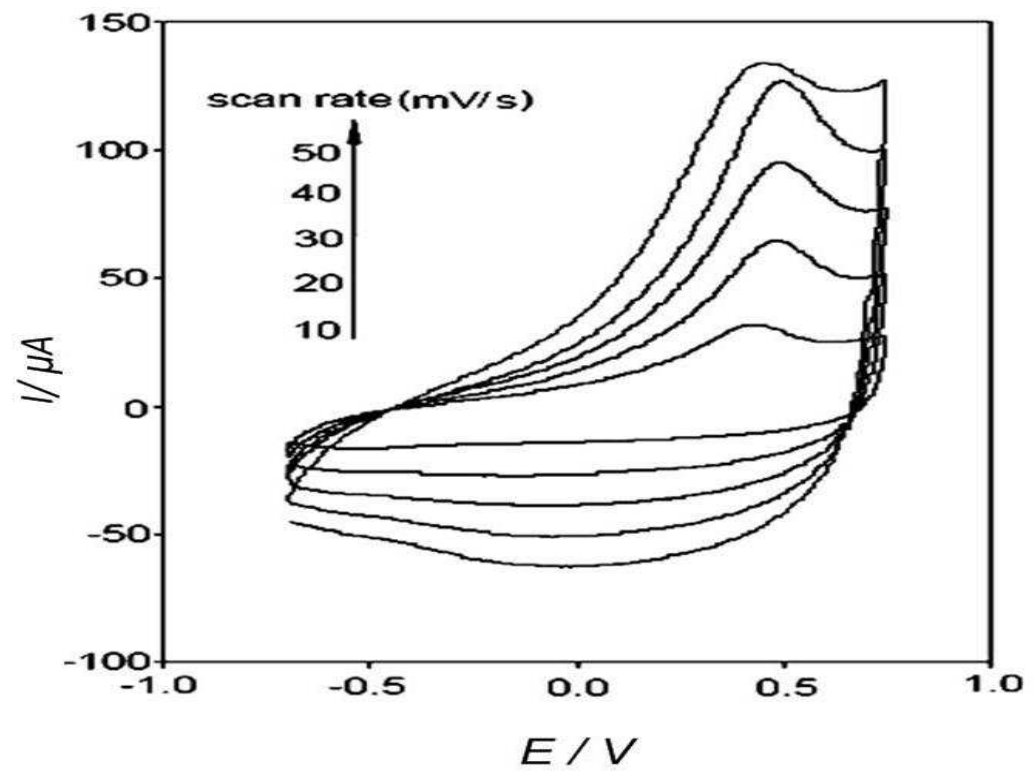

Fig. 2. Cyclic voltammograms of poly(Py)in $0.1 \mathrm{M} \mathrm{LiClO}_{4} / \mathrm{CH}_{3} \mathrm{CN}$ electrolyteat various scan rates

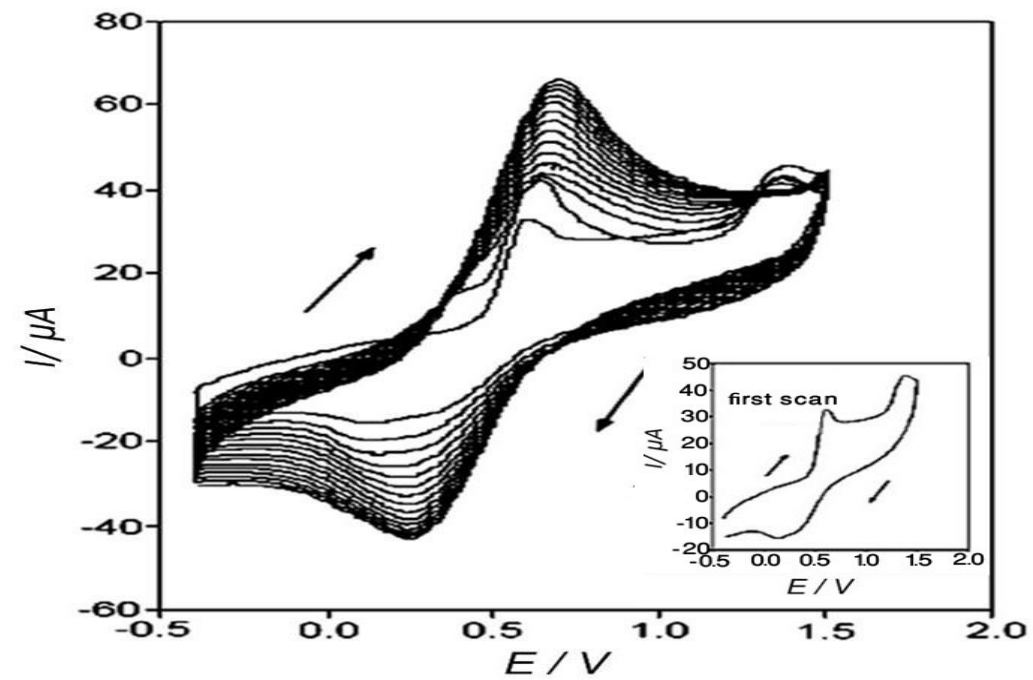

Fig. 3. Cyclic voltammograms of $7.4 \times 10^{-5} \mathrm{MSNS}$ in $0.1 \mathrm{M} \mathrm{LiClO}_{4} / \mathrm{CH}_{3} \mathrm{CN}$ electrolyte at scan rate $50 \mathrm{mV} / \mathrm{s}$ vs. $\mathrm{Ag} / \mathrm{AgCl}$ 


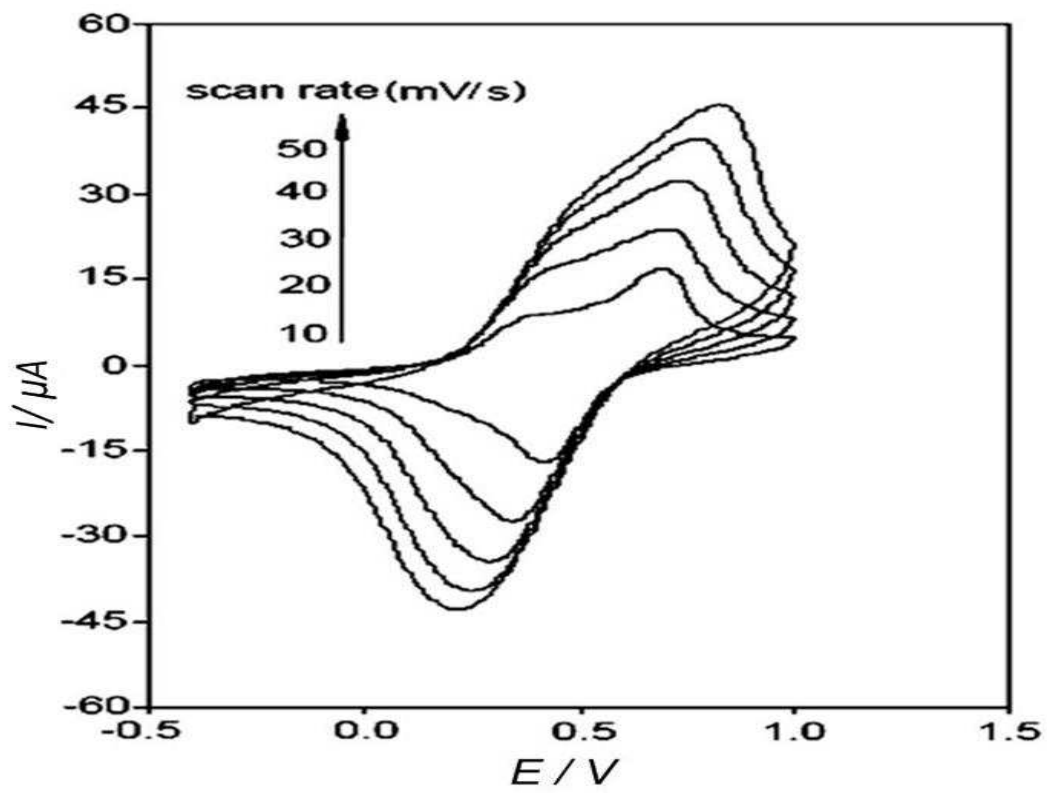

Fig. 4. Cyclic voltammograms of poly(SNS) in $0.1 \mathrm{M} \mathrm{LiClO}_{4} / \mathrm{CH}_{3} \mathrm{CN}$ electrolyte at various scan rates

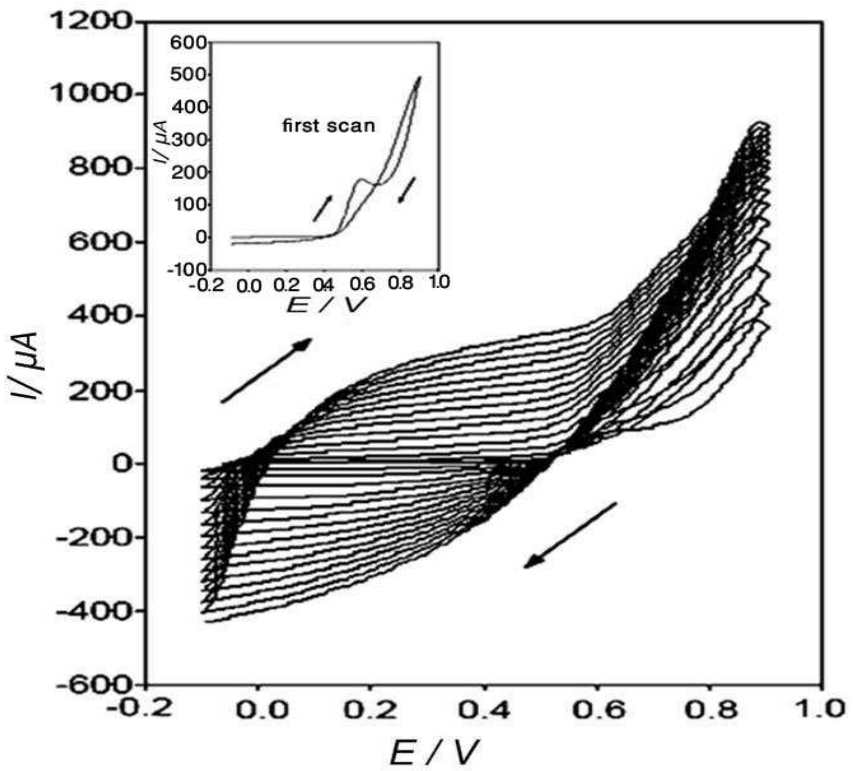

Fig. 5. Cyclic voltammograms of Py-SNS (100:1 mole ratio) in $0.1 \mathrm{M} \mathrm{LiClO}_{4} / \mathrm{CH}_{3} \mathrm{CN}$ electrolyte at scan rate $50 \mathrm{mV} / \mathrm{s}$ vs. $\mathrm{Ag} / \mathrm{AgCl}$ 
During the electropolymerization of pyrrole in the presence of the SNS (7.4 mmole: 0.074 mmole) two anodic peaks appeared at 570 and $800 \mathrm{mV}$. These peaks are due to the oxidation of SNS and pyrrole, respectively. In addition, the anodic peak at $570 \mathrm{mV}$ was absent during electropolymerization of pyrrole without SNS (Fig. 5). Because of conjugated backbone of SNS, the oxidation potential of this monomer is less than pyrrole. The cyclic voltammogram for the resulted polymer in various scan rates showed a relatively reversible behaviour (Fig. 6).

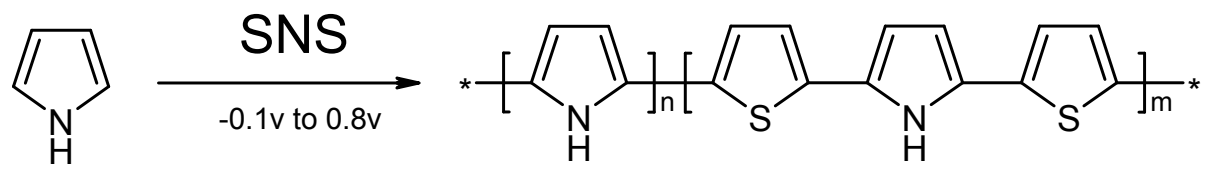

$n>>m$<smiles></smiles>

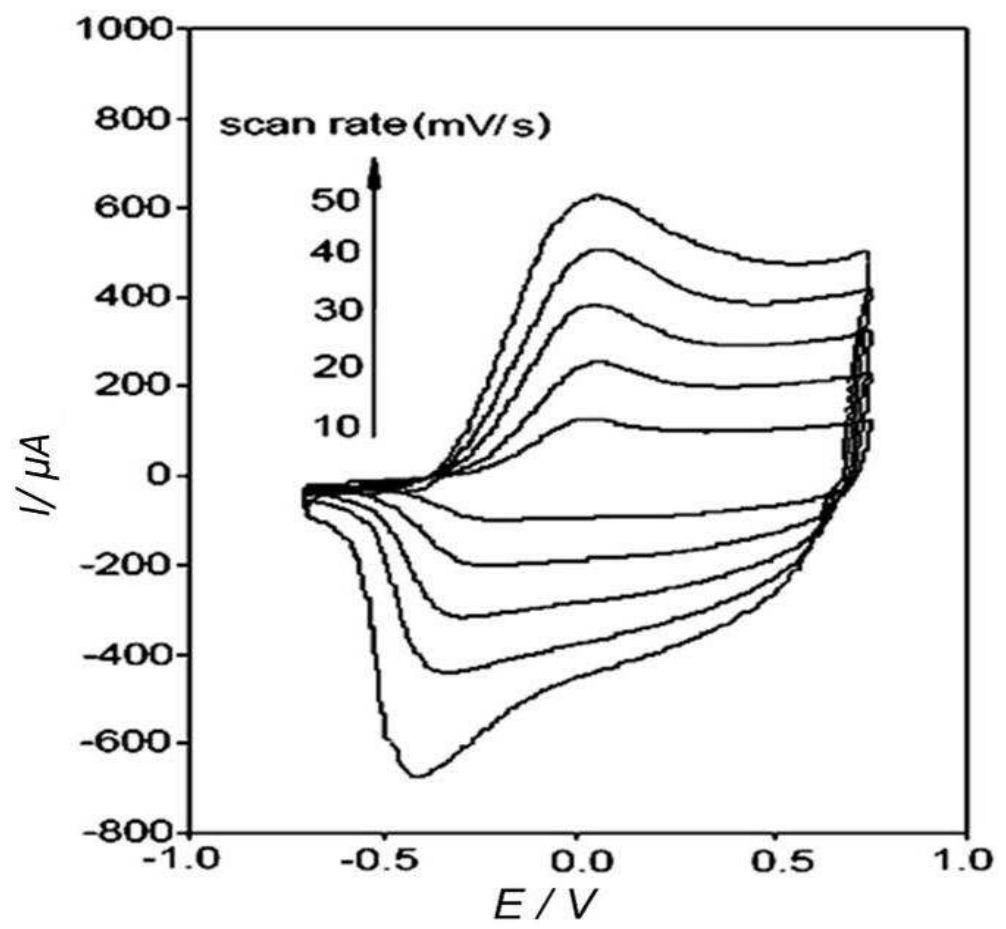

Fig. 6. Cyclic voltammograms of poly(Py-SNS) in $0.1 \mathrm{M} \mathrm{LiClO}_{4} / \mathrm{CH}_{3} \mathrm{CN}$ electrolyte at various scan rates 
Figure 7 presents the plot of anodic peak currents vs. different scan rates for obtained polymers. These curves show that the slop for poly(Py) and poly(Py-SNS) increases from 2.83 to $12.37 m A s . m V^{-1}$. These results indicated considerable increase in the electroactivity and rate of electropolymerization of polypyrrole in the presence of a small amount of SNS compared to the those of polypyrrole and poly(SNS). According to extracted data from cyclic voltammetries of polymers (see Table1), it can be seen that at various scan rates, $\mathrm{E}_{\mathrm{Pa}}$ for poly(Py-SNS) is less than those two for other polymers, but $i_{p a}$ for former polymer is more than those for two others. In other words, the conductivity of SNS included polypyrrole is better than polypyrrole alone and poly(SNS). Also, it is evident that at scan rates of less than $50 \mathrm{mV} \cdot \mathrm{s}^{-1}, \Delta \mathrm{E}_{\mathrm{p}}$ for poly(Py-SNS) is lower those for than two others, indicating improvement of redoxability for poly(Py-SNS) in comparison with poly(Py) and poly(SNS). At scan rate of $50 \mathrm{mV} . \mathrm{s}^{-1}$ the redoxability of poly(Py-SNS) is relatively similar to that of poly(Py).

The overall scheme of electrosynthesis of polypyrrole in the presence of SNS as shown Fig. 6.

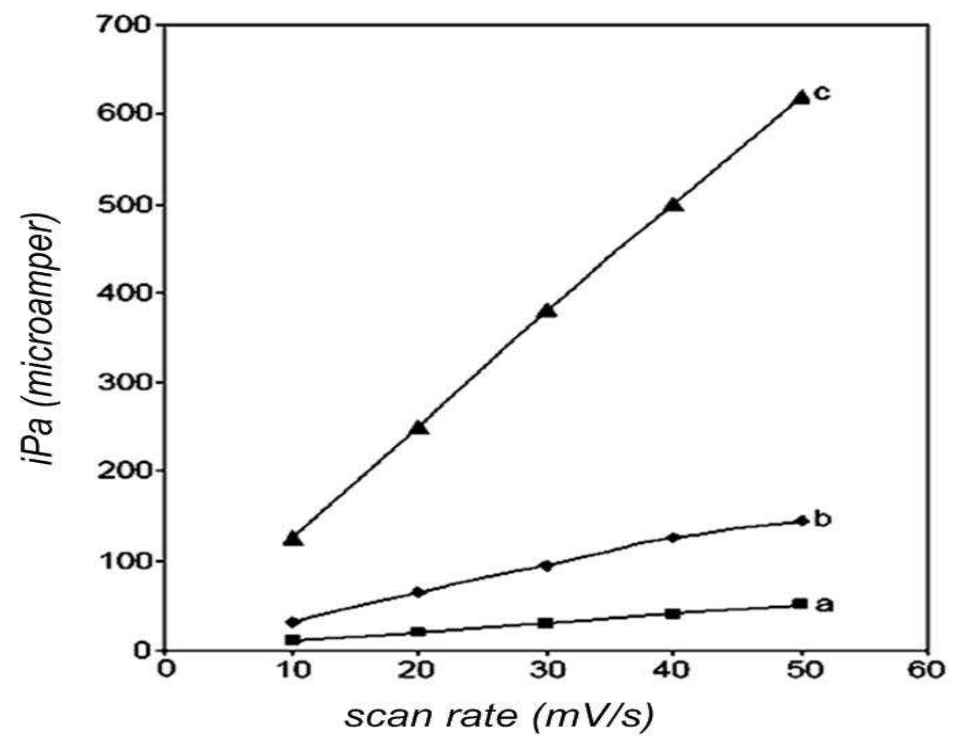

Fig. 7. Plots of anodic peak currents vs. scan rates for (a) poly(SNS), (b) poly(Py), (c) poly(Py-SNS) 


\begin{tabular}{|c|c|c|c|c|}
\hline \multirow{2}{*}{ Scan } & rates & Poly(Py) & Poly(SNS $)$ & Poly(Py-SNS) \\
\hline \multirow{3}{*}{$\mathrm{E}_{\mathrm{pa}}(\mathrm{V})$} & 10 & 0.450 & 0.715 & 0.052 \\
\cline { 2 - 5 } & 30 & 0.500 & 0.750 & 0.075 \\
\cline { 2 - 5 } & 50 & 0.460 & 0.841 & 0132 \\
\hline \multirow{3}{*}{$\mathrm{E}_{\mathrm{pc}}(\mathrm{V})$} & 10 & -0.123 & 0.405 & -0.240 \\
\cline { 2 - 5 } & 30 & -0.070 & 0.277 & -0.329 \\
\cline { 2 - 5 } & 50 & -0.050 & 0.201 & -0.431 \\
\hline \multirow{3}{*}{$\Delta \mathrm{E}_{\mathrm{p}}(\mathrm{V})$} & 10 & 0.573 & 0.310 & 0.292 \\
\cline { 2 - 5 } & 30 & 0.570 & 0.473 & 0.404 \\
\hline \multirow{3}{*}{$\mathrm{i}_{\mathrm{pa}}(\mu \mathrm{A})$} & 50 & 0.510 & 0.640 & 0.563 \\
\cline { 2 - 5 } & 10 & 32 & 19 & 120 \\
\cline { 2 - 5 } & 30 & 94 & 33 & 620 \\
\hline
\end{tabular}

Epa: potential of anodic peak Epc: potential of catidic peak $i_{\text {Pa: }}$ anodic peak currents

Table 1. Obtained date for poly(Py), poly(SNS) and poly(Py-SNS) at scan rates 10 and 50 $\mathrm{mV} / \mathrm{s}$

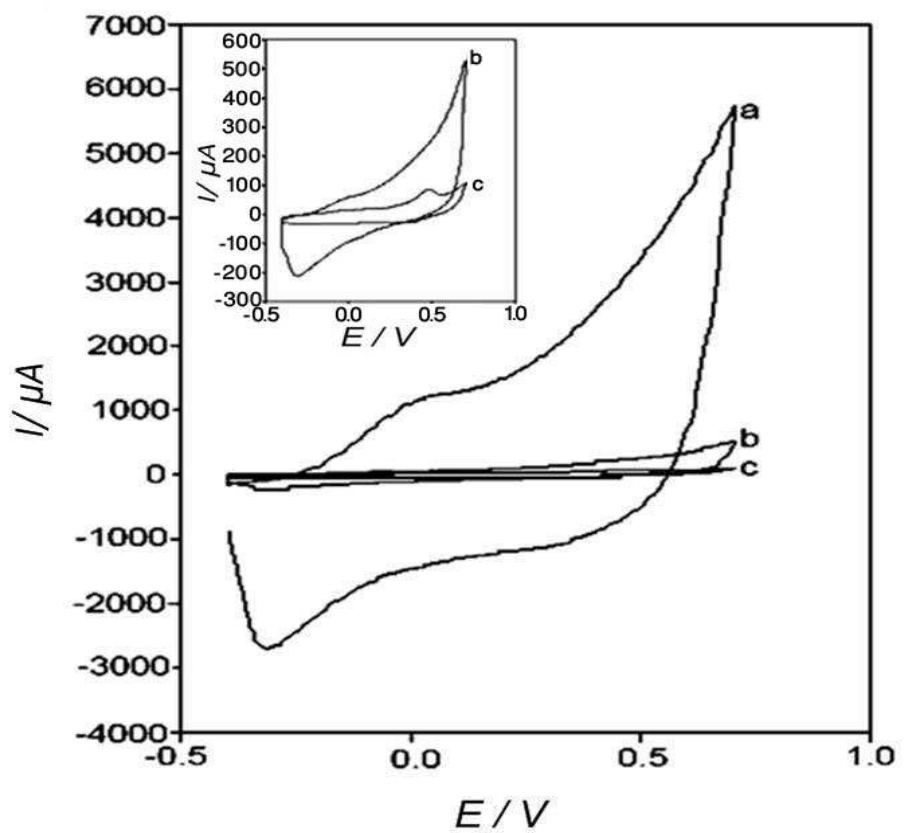

Fig. 8. Cyclic voltammograms of (a) poly(Py-SNS), (b) poly(SNS), and (c) poly(Py) on the GC electrode in $1 \mathrm{M} \mathrm{H}_{2} \mathrm{SO}_{4}$ and $1 \mathrm{mM} \mathrm{Fe}(\mathrm{CN})_{6}{ }^{4-} /{ }^{3-}$ redox system at $50 \mathrm{mV} / \mathrm{s}$ scan rate 
The CV experiments were performed to study the effect of SNS in the polypyrrole film in the electron transfer of ferro/ferricyanide redox system. Figure 8 shows the CV of electron transfer ferro/ferricyanide redox on different modified GC electrodes with poly(Py), poly(SNS), and poly(Py-SNS). This figure indicates that the electron transfer of ferro/ferricyanide on polypyrrole in the presence of the SNS is more feasible than that of polypyrrole alone, because the conductivity of polypyrrole increases in the presence of SNS.

\subsection{Evaluation of conductivity and electrochemical behaviour by electrochemical impedance spectroscopy (EIS)}

Electrochemical impedance spectroscopy (EIS) is a measurement technique which allows for a wide variety of coating evaluations. EIS is an effective method to probe the interfacial properties of surface-modified electrodes. EIS has been used to characterize the electrical properties of the electropolymerized films [Kiani et al., 2008a, 2008b]. The electrochemical behaviour of polypyrrole changes in the presence of SNS .In order to choose a suitable electrical equivalent circuit for EIS experimental data fitting, one must take in consideration the physicochemical picture of the system under study. In other words, each element of the equivalent circuit should have a physicochemical aspect attributable to it. In the model circuit chosen, $\mathrm{R}_{\mathrm{s}}$ presents the uncompensated resistance of the solution between working and reference electrode. $\mathrm{CPE}_{1}$ and $\mathrm{R}_{1}$ stand for the dielectric and resistive characteristics of the conductive polymer on the GC electrode, respectively. In this case $R_{1}$ is a reverse measure of polymer conductivity. $\mathrm{CPE}_{2}$ and $\mathrm{R}_{2}$ show the capacitance and resistance of the polymer/GC interface. As is evident from the high values of $R_{2}$ for all as well as the Nyquis plot of studied polymers, due to the fact that polymer layer is impermeable to the ionic charge carrier species, low frequency behaviour of the polymer/GC interface tends to be of capacitive nature. Again more evidence for this fact is reflected in the values of $n_{C P E 2}$ which for all studied samples is not very far than unity. Our main aim by EIS studies was to determine the polymer layer bulk resistivity (or its reciprocal i.e conductivity). In the selected equivalent circuit $R_{1}$ corresponds to this parameter. The studied electrical parameters were calculated using Zview(II) software. All fitting results are presented in Table 2.

\begin{tabular}{|c|c|c|c|c|c|c|c|}
\hline Sample & $\mathrm{R}_{\mathrm{s}}(\Omega)$ & $\mathrm{R}_{1}\left(\Omega . \mathrm{cm}^{2}\right)$ & $\begin{array}{c}\mathrm{R}_{2}\left(\Omega . \mathrm{cm}^{2}\right) \\
\mathrm{Y}_{0}\end{array}$ & $\begin{array}{c}\mathrm{CPE}_{1} \\
\mathrm{n}\end{array}$ & $\mathrm{CPE}_{1} \mathrm{Y}_{0}$ & $\begin{array}{c}\mathrm{CPE}_{2} \\
\mathrm{n}\end{array}$ & $\mathrm{CPE}_{2}$ \\
\hline Poly(Py) & 43.86 & 5.81 & $2.5 \mathrm{E} 4$ & $8.0 \mathrm{E}-4$ & 0.64 & $8.3 \mathrm{E}-4$ & 0.98 \\
\hline Poly(SNS) & 38.94 & 2282 & $7.2 \mathrm{E} 4$ & $1.3 \mathrm{E}-4$ & 0.72 & $1 \mathrm{E}-4$ & 1.00 \\
\hline Poly(Py-SNS) & 30.50 & 1.46 & $7.2 \mathrm{E} 4$ & 0.67 & 0.58 & 0.01 & 0.98 \\
\hline
\end{tabular}

$\mathrm{R}_{\mathrm{s}}$ : uncompensated resistance of the solution

$\mathrm{R}_{1}$ and $C P E_{1}$ : dielectric and resistive characteristics of the conductive polymer

$\mathrm{R}_{2}$ and $\mathrm{CPE}_{2}$ : capacitance and resistance of the polymer/ GC interface

$\mathrm{Y}_{0}: \mathrm{CPE}$ Admittance

$\mathrm{n}$ : CPE exponent

Table 2. Impedance parameters obtained by fitting the EIS data of poly(Py), poly(SNS) and poly(Py-SNS) on the GC electrode in $3.5 \% \mathrm{NaCl}$ 


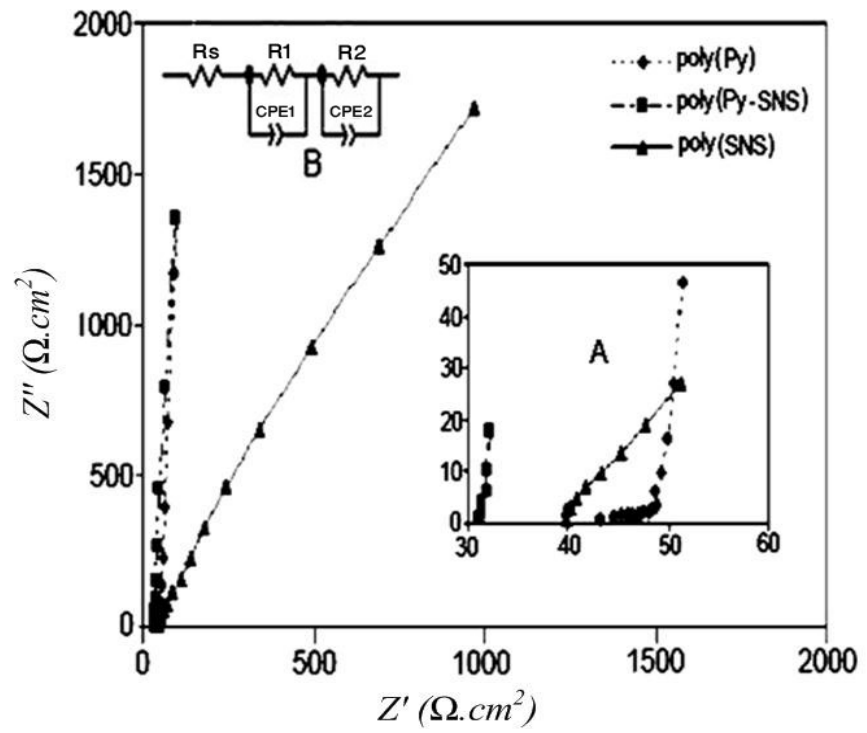

Fig. 9. Nyquist plots for poly(Py), poly(Py-SNS)(100:1 mole ratio) and poly(SNS) in 3.5\% (W/V) $\mathrm{NaCl}$ solution: A) Exploded view in the high frequency range, B) Proposed equivalent circuit

According to these results (Table 2), we can notice a decrease in the charge transfer resistance value in the case of the polypyrrole in the presence of SNS systems as compared to polypyrrole alone. The $R_{\text {ct }}\left(R_{\text {ct: }}\right.$ charge transfer resistance) values obtained for polypyrrole and poly(SNS) are 5.81 and $2282 \Omega . \mathrm{cm}^{2}$ respectively. This value decreases in the presence of SNS to $1.46 \Omega . \mathrm{cm}^{2}$. The polypyrrole film formed in the presence of SNS is more conductive. On the other hand, in the presence of SNS, value of the capacitance of the double layer, $\mathrm{CPE}_{1}$, rises from $8.0 \mathrm{E}-4$ to $0.67 \mu \mathrm{F} . \mathrm{cm}^{-2}$ which can be attributed to an increase in the electrode surface area. This change in the capacitance strongly supports the hypothesis of the incorporation of SNS in the polypyrrole film. Also, these results support the results of CV in the Figure 9. In the presence of SNS, the conductivity of polypyrrole is improved. Increased value of $\mathrm{CPE}_{1}$ for polypyrrole in the presence of $\mathrm{SNS}$ compared to pure polypyrrole confirmed the easy electron transfer of ferro/ferricyanide redox system for poly(Py-SNS) (Fig. 8). Improvement of the conductivity, electroactivity and redoxability of polypyrrole containing SNS leads it to extensive applications in many fields.

\section{Conclusions}

The resulted poly(Py-SNS)(100:1 mole ratio) showed a considerable increase in the electroactivity, redoxability, and the rate of polymerization in comparison to polypyrrole alone. The cyclic voltammograms of electron transfer ferro/ferricyanide redox system on different modified GC electrode showed that the rate of charge transfer for polypyrrole in the presence of SNS increased in comparison to pure polypyrrole. In addition, the conductivity of polypyrrole was studied by electrochemical impedance spectroscopy. The obtained $\mathrm{R}_{\mathrm{ct}}$ value for polypyrrole is $5.81 \Omega . \mathrm{cm}^{2}$, whereas the value decreases to $1.46 \Omega . \mathrm{cm}^{2}$ in 
the presence of SNS. By considering the fact that decreasing the $R_{\mathrm{ct}}$ leads to an increase in conductivity, it is predictable that the film of polypyrrole formed in the presence of SNS will be more conductive. In the presence of SNS, value of electrical double layer capacitance $\left(\mathrm{CPE}_{1}\right)$ rises, indicating a probable increase in the electrode surface area. There is a good complementary agreement between the results of CV and EIS measurements. From these results it can be concluded that the produced polypyrrole containing small amount of SNS has better performance compared to polypyrrole alone for production of batteries, capacitors, diodes, electrochromic devices, sensors and etc.

\section{Acknowledgment}

The authors acknowledge Mr. I. Ahadzadeh, for his kind help in EIS measurements.

\section{References}

Brillas, E. Carrasco, J. Oliver, R. Estrany, F. Vilar, J. \& Morlans, J.M. (2000). Electropolymerization of 2,5-di-(-2-thienyl)-pyrrole in ethanolic medium. Effect of solution stirring on doping with perchlorate and chloride ions. Electrochimica Acta, Vol. 45, pp. 4049-4057.

Chang, C.H. Son, P.S. Yang, G.H. \& Choi, S.H. (2009). Electrochemical Synthesis of the Functionalized Poly(pyrrole) Conducting Polymers. Journal of the Korean Chemical Society, Vol. 53, No.2, pp. 111-117.

Cortés, M.T. \& Moreno, J.C. (2003). Artificial muscles based on conducting polymers. ePolymers, No. 041, pp. 1-42.

Geetha, S. Chepuri, R.K.R. Vijayan, M. \& Trivedi, D.C. (2006). Biosensing and drug delivery by polypyrrole. Analytica Chimica Acta, Vol. 568, pp. 119-125.

Heinze, J. Frontana-Uribe, B.A. \& Ludwigs, S. (2010). Electrochemistry of Conducting Polymers-Persistent Models and New Concepts. Chemical Reviews, Vol. 110, No.8, pp. 4724-4771.

Hosseini, M.G. Sabouri, M. \& Shahrabi, T. (2007). Corrosion protection of mild steel by polypyrrole phosphate composite coating. Progress in Organic Coatings, Vol. 60, pp. 178-185.

Hosseini, M.G. Sabouri, M. \& Shahrabi, T. (2008). Comparison of the corrosion protection of mild steel by polypyrrole-phosphate and polypyrrole-tungstenate coatings. Journal of Applied Polymer Science. Vol. 110, No. 5, pp. 2733-2741.

Jang, J. \& Oh, J.H. (2004). Morphogenesis of Evaporation-Induced Self-Assemblies of Polypyrrole Nanoparticles Dispersed in a Liquid Medium. Langmuir, Vol. 20, pp. 8419-8422.

Kiani, G.R. Arsalani, N. \& Entezami, A.A. (2001). The Influence of the Catalytic Amount of 1-(2-Pyrrolyl)-2-(2-Thienyl) Ethylene and 2-(2-Thienyl) Pyrrole on Electropolymerization of Pyrrole and N-Methylpyrrole. Iranian Polymer Journal, Vol. 10, pp. 135-142.

Kiani, G.R. Arsalani, N. \& Entezami, A.A. (2008). Synthesis of Poly(3-methylthiophene) in the Presence of 1-(2-Pyrrolyl)-2-(2-thienyl) Ethylene by Electropolymerization. Journal of Iranian Chemical Society, Vol. 5, pp. 559-565.

Kiani, G.R. Arsalani, N. Hosseini, M.G. \& Entezami, A.A. (2008). Improvement of the conductivity, electroactivity, and redoxability of polythiophene by 
electropolymerization of thiophene in the presence of catalytic amount of 1(2-pyrrolyl)-2-(2-thienyl) ethylene (PTE). Journal of Applied Polymer Science, Vol. 108, No. 4, pp. 2700-2706.

Kraft, A. Grimsdale, A.C. \& Holmes, A.B. (1998). Electroluminescent Conjugated PolymersSeeing Polymers in a New Light. Angewandte Chemie International Edition, Vol. 37, No.4, pp. 402-428, ISSN 14337851

Malinauskas, A. Garjonyte, R. Mazeikiene, R. \& Jureviciute, I. (2004). Electrochemical response of ascorbic acid at conducting and electrogenerated polymer modified electrodes for electroanalytical applications: a review. Talanta, Vol. 64, pp. 121-129.

McLeod, G.G. Mahboubian-Jones, M.G.B. Pethrick, R.A. Watson, S.D. Truong, N.D. Galin, G.C. \& Francois, J. (1986). Synthesis, electrochemical polymerization and properties of poly(2,5-di-(-2-thienyl)-pyrrole). Polymer, Vol. 27, pp. 455-458.

Mortimer, R.J. Dyer, A.L. \& Reynolds, J.R. (2006). Electrochromic organic and polymeric materials for display applications. Displays, Vol. 27, No.1, pp. 2-18.

Nicolas-Debarnot, D. \& Poncin-Epaillard, F. (2003). Polyaniline as a new sensitive layer for gas sensors. Analytica Chimica Acta, Vol. 475, pp. 1-15.

Oco'n, P. Cristobal, A.B. Herrasti, P. \& Fatas, E. (2005). Corrosion performance of conducting polymer coatings applied on mild steel. Corrosion Science, Vol. 47, pp. 649-662.

Otero, T.F. Villanueva, S. Brillas, E. \& Carrasco, J. (1998). Electrochemical processing of the conducting polymer poly(SNS). Acta Polymerica, Vol. 49, pp. 433-438. IISSN 03237648

Perin, D.D. \& Armarego, W.L.F. (1998). Purification of Laboratory Chemicals, Edition, Pergamon publisher, Oxford.

Sahin, E. Camurlu, P. Toppare, L. Mercore, V.M. Cianga, I. \& Yagci, Y.J. (2005). Conducting copolymers of thiophene functionalized polystyrenes with thiophene. Journal of Electroanalytical Chemistry, Vol. 579, pp. 189-197.

Wynberg, H.\& Metselaar, J. (1984). A Convenient Route To Polythiophenes. Synthetic Communications, Vol. 14, pp. 1-9.

Zhang, X. Zhang, J. Song, W. \& Liu, Z. (2006). Controllable Synthesis of Conducting Polypyrrole Nanostructures. Journal of Physical Chemistry B, Vol. 110, pp. 1158-1165, ISNN 16471658. 


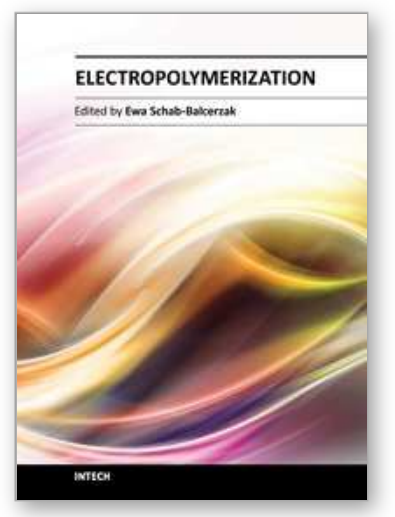

\author{
Electropolymerization \\ Edited by Dr. Ewa Schab-Balcerzak
}

ISBN 978-953-307-693-5

Hard cover, 214 pages

Publisher InTech

Published online 22, December, 2011

Published in print edition December, 2011

In recent years, great focus has been placed upon polymer thin films. These polymer thin films are important in many technological applications, ranging from coatings and adhesives to organic electronic devices, including sensors and detectors. Electrochemical polymerization is preferable, especially if the polymeric product is intended for use as polymer thin films, because electrogeneration allows fine control over the film thickness, an important parameter for fabrication of devices. Moreover, it was demonstrated that it is possible to modify the material properties by parameter control of the electrodeposition process. Electrochemistry is an excellent tool, not only for synthesis, but also for characterization and application of various types of materials. This book provides a timely overview of a current state of knowledge regarding the use of electropolymerization for new materials preparation, including conducting polymers and various possibilities of applications.

\title{
How to reference
}

In order to correctly reference this scholarly work, feel free to copy and paste the following:

Nasser Arsalani, Amir Mohammad Goganian, Gholam Reza Kiani, Mir Ghasem Hosseini and Ali Akbar Entezami (2011). Electrosynthesis and Characterization of Polypyrrole in the Presence of 2,5-di-(2-thienyl)Pyrrole (SNS), Electropolymerization, Dr. Ewa Schab-Balcerzak (Ed.), ISBN: 978-953-307-693-5, InTech, Available from: http://www.intechopen.com/books/electropolymerization/electrosynthesis-and-characterizationof-polypyrrole-in-the-presence-of-2-5-di-2-thienyl-pyrrole-sns

\section{INTECH}

open science | open minds

\section{InTech Europe}

University Campus STeP Ri

Slavka Krautzeka 83/A

51000 Rijeka, Croatia

Phone: +385 (51) 770447

Fax: +385 (51) 686166

www.intechopen.com

\section{InTech China}

Unit 405, Office Block, Hotel Equatorial Shanghai

No.65, Yan An Road (West), Shanghai, 200040, China

中国上海市延安西路65号上海国际贵都大饭店办公楼 405 单元

Phone: +86-21-62489820

Fax: $+86-21-62489821$ 
(C) 2011 The Author(s). Licensee IntechOpen. This is an open access article distributed under the terms of the Creative Commons Attribution 3.0 License, which permits unrestricted use, distribution, and reproduction in any medium, provided the original work is properly cited. 